\title{
QUIZ CASE
}

\section{Paediatric neuropathology}

\section{S K Misser, MB ChB, FCRad (D)}

Lake Smit and Partners, Durban

\section{J F Roos, MB ChB, MMed (Paed)}

Parklands Hospital, Durban

Corresponding author: S Misser (shalendramisser@hotmail.com)

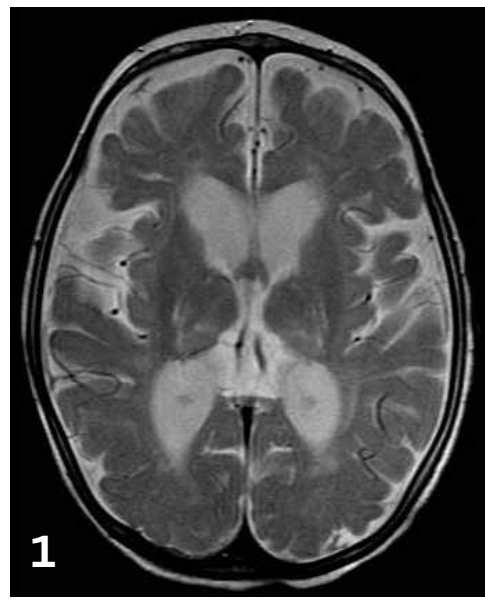

Figs 1 and 2 are axial T2-w MRI sequences.

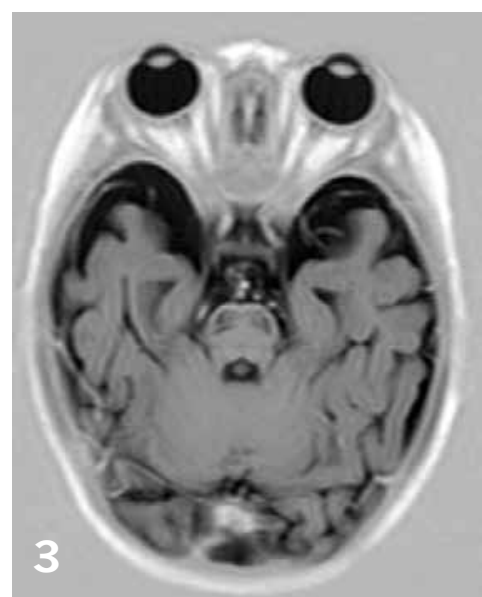

Fig. 3 is an axial inversion recovery sequence.

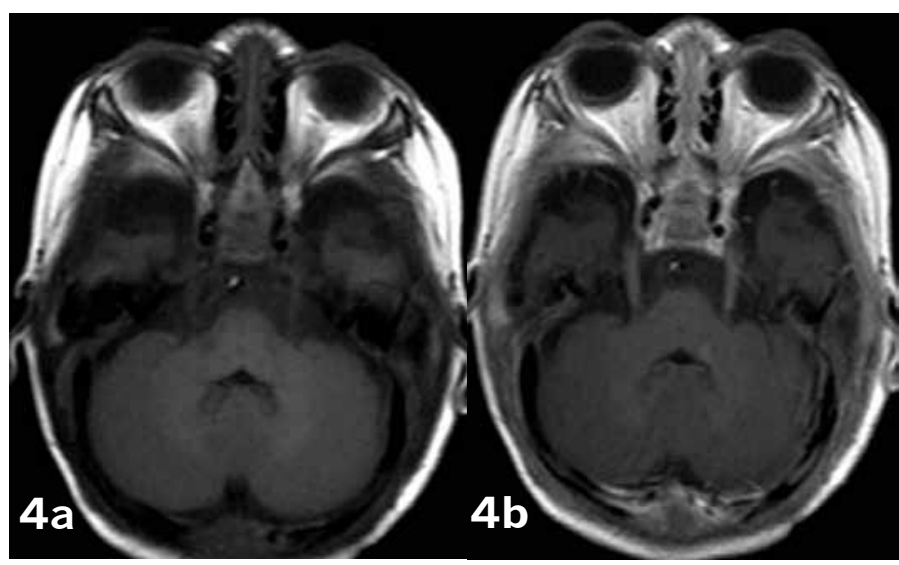

Figs $4 a$ and $4 b$ are axial pre- and post-gadolinium sequences respectively.

\section{Presentation}

A 10-month-old child presented with spasticity, regression of milestones and irritability. The following images were obtained (Figs $1-5)$. Nonspecific EEG abnormality was also documented.

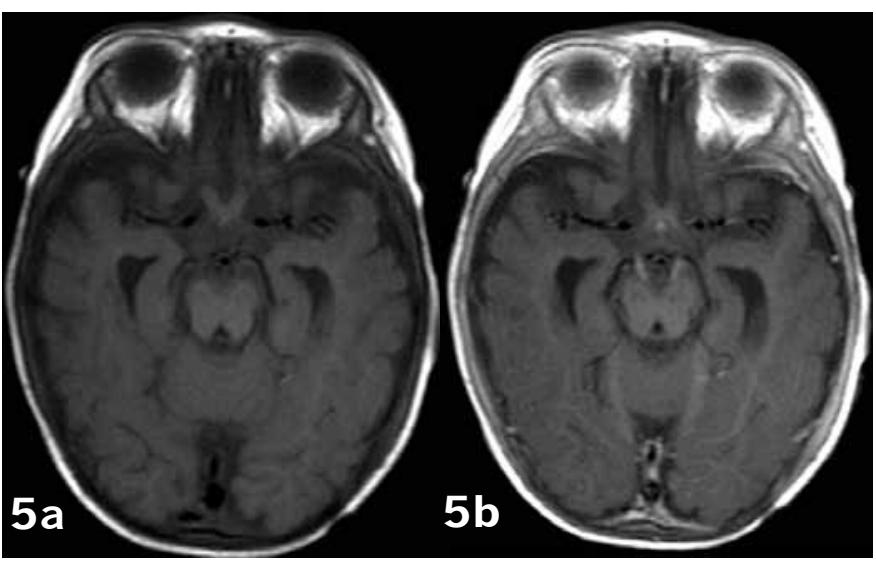

Figs $5 a$ and $5 b$ are axial pre- and post-gadolinium sequences respectively.

Describe the relevant findings and provide the most appropriate clinical diagnosis. Please submit your response to shalendramisser@ hotmail.com not later than 1 November 2011. The winning respondent will receive a R1 000 award from the RSSA. A detailed diagnosis and discussion will be presented in the next issue of the SAJR. 